\title{
A BRIEF SURVEY OF THE BATS OF ELK ISLAND NATIONAL PARK
}

GEOFFREY L. HOLROYD, Canadian Wildlife Service, No. 1000, 9942-108 Street, Edmonton, Alberta. T5K 2J5

A brief survey was undertaken to establish which species of bats occur in Elk Island National Park (EINP) and to determine their relative abundance. Banfield and van Zyll de Jong show that five species of bats can be expected in EINP.1 10 These are: Hoary Bat (Lasiurus cinereus), Big Brown Bat (Eptesicus fuscus), Silver-haired Bat (Lasioinycteris noctivagans), Northern Longeared Bat (Myotis septentrionalis) and Little Brown Bat (Myotis lucifugus). In addition two species occur to the west but do not reach Edmonton or EINP (Long-legged Bat, M. volans and Long-eared Bat, $M$. evotis). Warden records show that only Little Brown Bat has been previously recorded from EINP.

Bats orient using ultrasonic echolocation calls which bounce off objects including potential food. ${ }^{2}$ These calls function much like radar. Normally these calls are above the sensitivity of the human ear. However bat detectors have been used for some time to convert the ultrasonic call into an audible tone. Recently a small detector has become commercially available which permits us to learn about bats from their calls (QMC Mini bat detector, QMC Intruments Ltd., 229 Mile End Road, London, England, E14AA).

\section{Methods}

For three evenings, 27 to 29 July 1983 we surveyed areas within EINP for bats, both catching them and listening with a detector for echo-location calls.
Three methods were used to catch bats. Visual searches for roosting bats were conducted in and around buildings at the government compound, administrative building, south gate, south information centre and nearby horse barn. Secondly, at the information centre two $9 \mathrm{~m}$ long, $38 \mathrm{~mm}$ mesh black mist nets were set against the west wall on the evening of 29 July. Two nets were set over a boardwalk at a marsh on the Amisk Wuche trail on 26 July. Thirdly, a collapsable Tuttle Trap was set in front of the west loading door on the second floor of the horse barn on 29 July. ${ }^{9} 8$

QMC mini bat detector converts the ultrasonic bat echolocation calls from 20 to $40 \mathrm{kHz}$ to signals audible to us. A detector was tuned alternately from 20 $\mathrm{kHz}$ to $40 \mathrm{kHz}$ and back about every two seconds providing continous monitoring of these frequencies. The detector was used for five minutes at each site except at the start of the evening when it was left on continually until the first bats were heard. During the five minute period, the number of passes by bats were counted. Identification of bats using the QMC bat detector followed Fenton, Merriam and Holroyd (see Table 1.). ${ }^{4}$ :

\section{Results}

Captures

Three species of bats were trapped: Big Brown, Little Brown and Northern Long-eared.

A male Big Brown Bat was caught by hand at the peak of the west side of the 
Table 1. IDENTIFICATION OF BATS USING THE QMC BAT DETECTOR

Frequency
$20-25 \mathrm{kHz}$
$25-30 \mathrm{kHz}$
$40 \mathrm{kHz}$
$25-30 \mathrm{kHz}$
$35 \mathrm{kHz}$
$40 \mathrm{kHz}$
$40 \mathrm{kHz}$

Frequency

Output

a tonal chirp

a tonal chirp

a tonal chirp

a 'put' sound

a 'put' sound

a sharp tick

a soft tick

\section{Species}

Hoary Bat

Silver-haired Bat

Red Bat

Big Brown Bat

Long-legged Bat

Little Brown Bat and other Myotis

Northern Long-eared Bat and other Myotis south gate house on 28 July and another escaped from the peak at the east side of the building on the following evening. Another male Big Brown was caught in the Tuttle Trap at the horse barn.

Fourteen Little Brown Bats were caught on 29 July and an immature was found by park staff at the stores buildings. Three were caught in the mist nets at the information building. One of these was seen roosting in the evening and was caught at dusk. The other two were caught later at night presumably when they were using the building as a night roost. Ten Little Brown Bats (six male, four female) were taken in the Tuttle trap at 0145 when it was first checked but none were present in it on the morning of 30 July. This could indicate that the bats left the barn over the loosely fitting door but entered the barn some other way.

The Tuttle trap also held a single male Northern Longeared Bat at 0145.

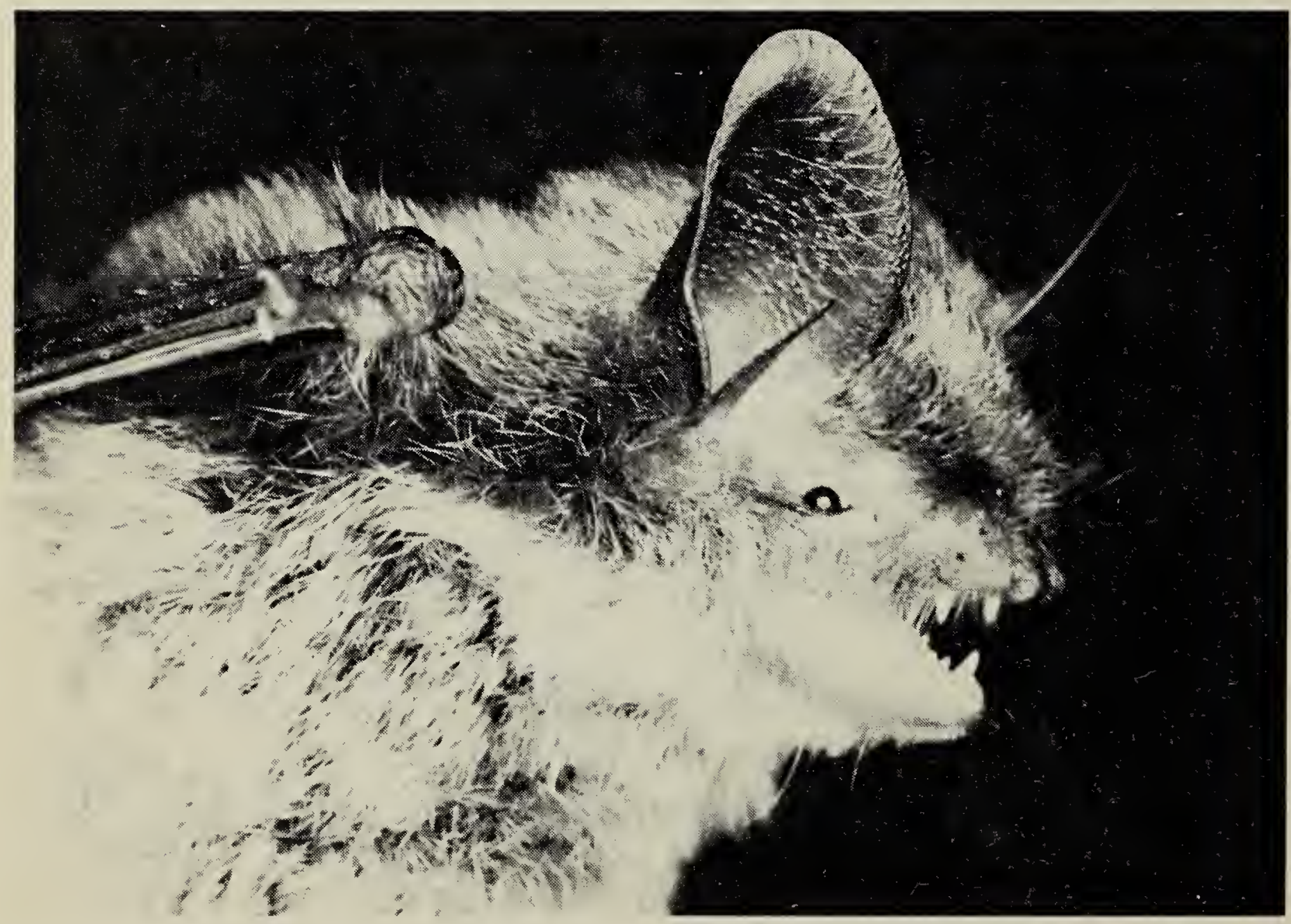




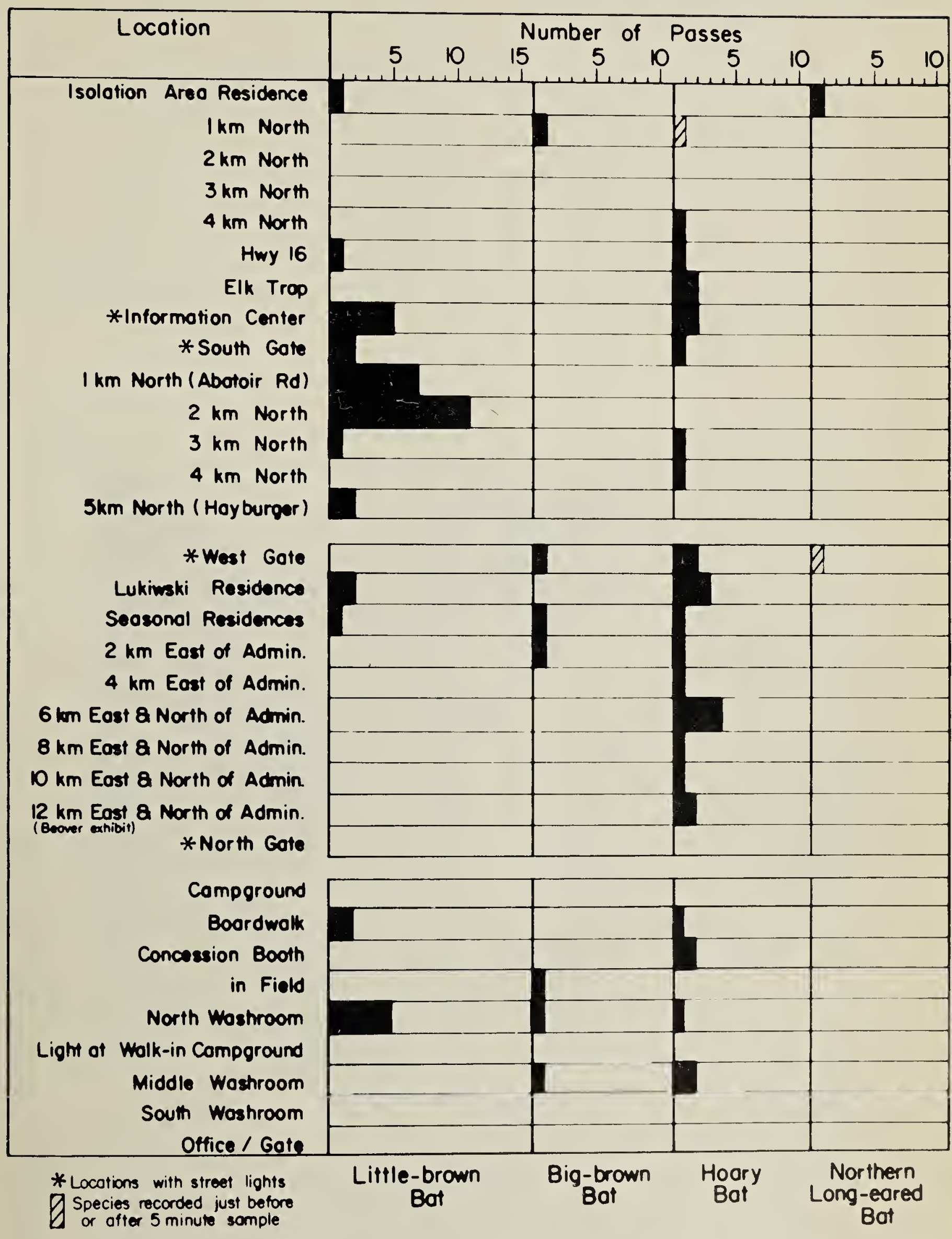

Figure 1. Results of transects for bat activity along roads in Elk Island National Park. Bars indicate the number of passes in five minute samples monitored with a QMC mini bat detector. 


\section{Echolocation records}

The echolocation calls of four species of bats were detected with the QMC Mini Bat Detectors (Figure 1). Hoary Bat and Big Brown Bat calls are quite distinctive. The ticks of the Myotis group can be split into hard ticks and soft ticks. At Elk Island the hard ticks should be the calls of the Little Brown Bat and the soft ticks those likely from the Northern Longeared Bat. The Long-legged Bat and Long-eared Bat produce hard and soft ticks respectively but Banfield indicates that Elk Island is just to the east of the known range of both these species. ${ }^{1}$

Based on their calls, the Little Brown Bat was the most common species of bat in EINP followed by Hoary Bat. Big Brown Bat was less common and Long-eared Bat was least common. However, the Long-eared has a quiet call which makes it less conspicuous.

Little Brown Bats were quite clumped in their distribution with 28 of 40 records at only 4 sites (Figure 1). Hoary Bats were more evenly distriand buted along the roadways with 31 records at 20 sites compared to 12 sites for the Little Brown Bats. Big Brown Bats were recorded once at each of 7 sites indicating little clumping but 3 sites were near the west gate residences and three sites were at the campground. At EINP 5 areas with street lights were sampled and bats were recorded at four (Figure 1). No bats were heard at the north gate lights, but it was very windy (Beaufort force 4-5) at the time. At the other 4 lights, activity was 0.9 passes per minute.

Bat activity was first recorded between $2236 \mathrm{~h}$ and $2245 \mathrm{~h}$ on these nights. At this time of year, this is after sunset but the bats could be seen in the twilight.

\section{Discussion}

The level of bat activity at Elk Island National Park is low but evenly distributed. Overall, bats were encountered on average every two minutes ( 0.49 passes per minute) compared to 1.94 passes per minute in 1981 and 0.71 in 1982 in Kootenay, Glacier and Mt. Revelstoke National Parks and 3.41 to 10 passes per minute in southern Ontario. ${ }^{4} 3$ The range of passes per minute in Elk Island was 0 to 2.2 compared to 0 to 6.95 in the mountain parks and 0 to 67 in southern Ontairo (ibid).

Although the level of activity is low, the distribution of bats is more even in Elk Island than in the mountain parks. Bats were recorded at 26 of 31 sites $(81 \%)$ in Elk Island compared to 10 of 30 sites $(33 \%)$ on road surveys in the mountain parks. The habitat at Elk Island is superficially less varied and may have fewer "hot spots" for foraging than in the mountains where there were definite foci of bat activity.

One type of activity centre was street lights where bats occurred at the rate of over four passes per minute in the mountains. At the four lights in EINP where bats were heard, activity was 0.9 passes per minute which was greater than the overall average at EINP but still well below 3.4 passes per minute recorded at four lights in the mountain parks in 1981. Thus although lights are a focus of activity for bats in Elk Island they do not appear as important as they are in the mountain parks.

Different levels of activity by bats in these different areas could introduce errors in the comparisons. Insect activity, especially mosquitoes, was very high in Elk Island, much higher than in the mountains. In fact, it may be difficult for the reader to fully appreciate the mosquito activity that 
was experienced on those three nights unless the reader is currently resting on a bed of nails.

The abundant food supply could result in less time required to become satiated and more time spent roosting and digesting prey at night in Elk Island National Park.

Little Brown Bats were most common in the southerly $3 \mathrm{~km}$ of the main road north of Highway 16. Buildings are relatively common in this area including the barn where 10 were caught and the information centre where another three were netted. These buildings provide suitable roost sites for this colonial species. Likewise Big Brown Bats were most frequent near buildings reflecting their roost sites.

In contrast the Hoary Bat did not show any concentration of activity which was expected since it is a solitary forest-dwelling species. ${ }^{2}$ Aspen forest was at or near every site that was sampled.

Do the species associate with or avoid each other? The Spearman rank

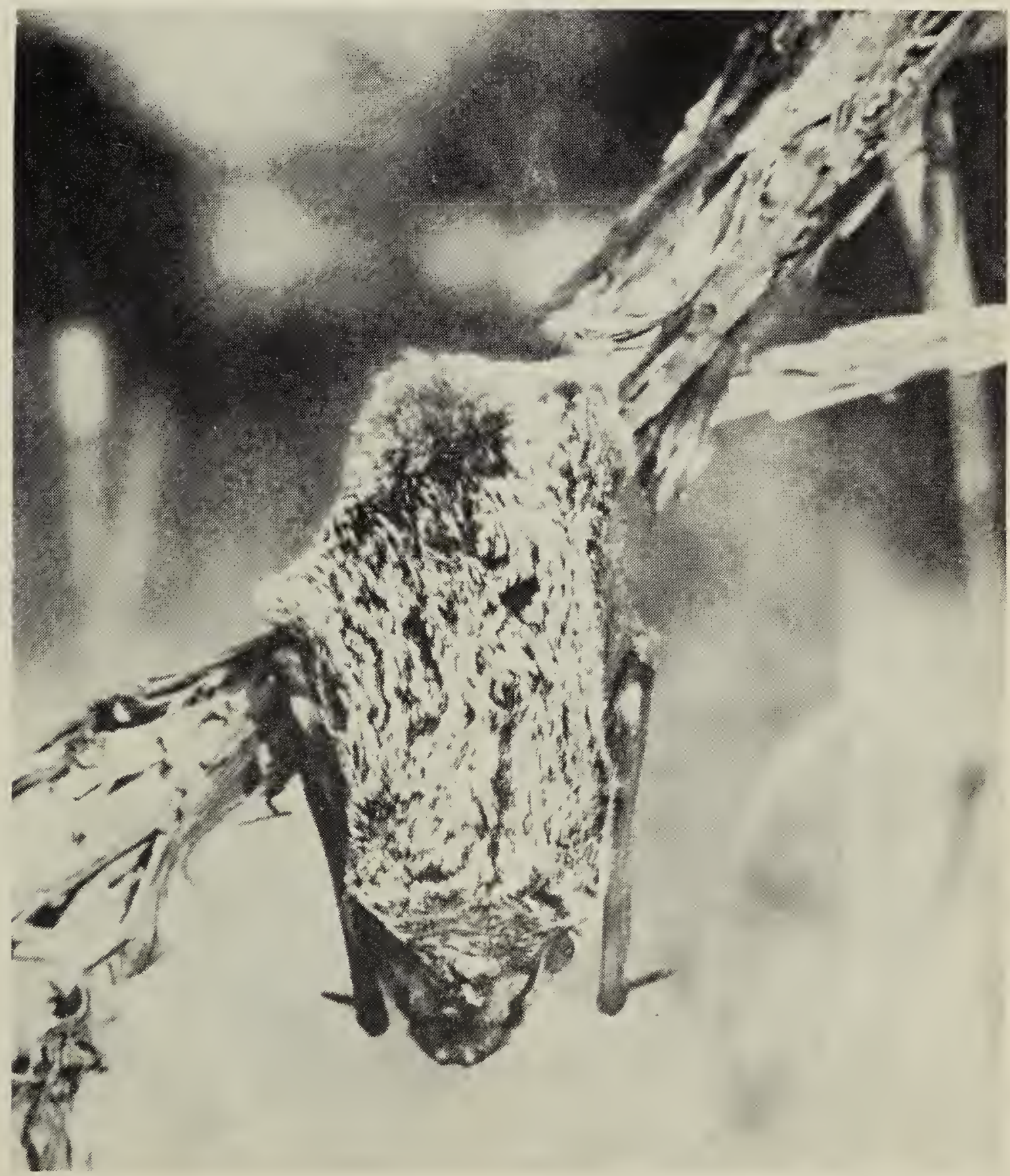

Hoary Bat. 
correlation coefficient, $r$, using the number of passes of Little Brown Bats and Hoary Bats at each site $(N=33)$, is 0.143 indicating neutral association of the two species. Thus they appear to be neither associating near a localized abundant food nor avoiding common feeding sites.

This survey did not adequately sample bat activity in all habitats in the park. Most sample sites were on roadsides adjacent to aspen forest. The site $2 \mathrm{~km}$ north of the south gate was a grassland and the boardwalk at the campground is over water. All three habitats had bats flying over them but additional sampling would be required to establish any species-specific preference.

Bats have considerable public interest and consequently are potential subjects for public education programmes. The QMC mini bat detector is suitable for "listening" for bats and can be connected to an amplifier and speakers for large groups. "Feeding buzzes" can also be heard on the detector. EINP would be a good location for education events because of the widespread activity of two species of bats.

In conclusion much can be learned about bats in a relatively short time. The QMC mini bat detector is a useful piece of equipment for wide ranging surveys of bats that permits adequate identification of the species of bats and monitoring of their activity. Future sampling of bat activity at Elk Island could show the presence of Silverhaired Bat and Red Bat possibly on migration in May or late August and September. ${ }^{6}$ The habitat preferences of each species might also be learned with additional sampling. Finally the Hoary Bat does appear to be a common bat of the aspen parkland as hypothesized by Soper but questioned by Schowalter and Doward. ${ }^{7} 5$

\section{Acknowledgements}

This survey is part of the small mammal inventory of EINP being conducted by Gordon Burns, Canadian Wildlife Service, and the park wardens with funding by Parks Canada. I thank Gordon Burns, Chuck Blyth and the other park wardens for their assistance and enthusiasm during this survey. The comments from Brock Fenton, Ed Telfer and Gordon Burns on an earlier draft are greatly appreciated.

${ }^{1}$ BANFIELD, A.W.F. 1974. Mammals , f Canada. University of Toronto Press. $438 \mathrm{pp}$.

2 FENTON, M.B. 1983. Just Bats. University of Toronto Press. $165 \mathrm{pp}$.

${ }^{3}$ FENTON, M.B. and H.G. MERRIAM. 1981. Survey for bats in Kootenay, Glacier and Mount Revelstoke National Parks. Unpublished report prepared for CWS, Edmonton. 19 pp.

${ }^{4}$ FENTON, M.B., H.G. MERRIAM and G.L. In press. Bats of Kootenay, Glacier and Mount Revelstoke National Parks in Canada: Identification of echolocation calls, distribution and biology. Canadian Journal of Zoology.

5 SCHOWALTER, D.B. and W.J. DORWARD. 1978. Some western Canadian bat records. Blue Jay 36:49-50.

6 SCHOWALTER, D.B., W.J. DORWARD and J.R. GUNSON. 1978. Seasonal occurence of Silver-haired Bats (Lasionycteris noctivagans) in Alberta and British Columbia. Canadian FieldNaturalist 92:288-291.

7 SOPER, J.D. 1964. The mammals of Alberta. Hamley Press, Edmonton. 402 pp.

8 TIDEMANN, C.R. and D.P. WOODSIDE. 1978. A collapsable bat-trap and a comparison of results obtained with the trap and with mist nets. Australian Wildlife Research Vol. 5: 355-362.

9 TUTTLE, M.D. 1974. Improved trap for bats. J. Mammalogy 55: 475-477.

10 VAN ZYLL DE JONG, C.G. 1979. Distribution and systematic relationships of long eared Myotis in western Canada. Canadian Journal of Zoology 57:987-994. 